\title{
Transcultural Psychiatry: Comparison of Eastern and Western Culture and their influence on mental health and its treatment
}

S.P. Tiong, S. Rajkumari, N.F.B. Rasidi, Dr. O.V. Poplavskaya

Department of Psychiatry, Narcology and Psychotherapy. Volgograd State Medical University

Abstract

The differences due to culture, norms and values, especially in a controversial topic such as the paranormal, is a dicult one to bridge between doctors and patients. This work studies the belefs or Eastern and Western populations about religion, the paranormal and its relation to mental health. It was conducted targeting cilizen of several Eastern and Western countries, with a target size of 200 . A survey and 2 case studies were distributed at random. It was aimed to determine respondent's level of belief in cultural superstitions and practices, views on mental disorder and their opinion on its treatment. A chi-square statistical test (significance set at $\leq 0.05$ ) was performed to test validity. The results revealed that Eastern populations are far more superstitious and/or religious than their Western counterparts, as well as having higher belief in the effectiveness of spiritual healing in the treatment of mental disorders. This difference demonstrates the importance of integrating culture into diagnosis and treatment of mental illness and further explore methods for more inclusive treatment plans.

\section{Introduction}

\section{$\otimes+\div 36$}

There is more to the mind than can ever be fully understood. In a globalizing world the need for humans to understand one another has never been more imperative. This is the aim of Transcultural Psychiatry, a branch of psychiatry primarily concerned with the relationship of cultural aspects with human behavior

In this study, the term paranormal will encompass concepts such as religion, magic, and superstition. The interrelationship of these concepts is alike to the interrelationship between the mind, spirit and soul. Despite their different connotations, they denote the same thing. Each of these concepts are hardwired in the intricacies of all belief systems and are general propositions about the ways the world works. They dictate how many of us live our lives and most importantly are also beyond the scope of current scientific knowledge (Lindeman et al, 2012).

Understanding cultural beliefs affects the communication of the doctor and patient. The focus of this report will be the influence of paranormal beliefs specifically on the psyche of individuals within the frame of eastern and western societies.

\section{Objectives}

To the beliefs of Eastern and Western populations about the religions/paranormal and its relation to mental health. This study aims to create a better understanding that may work to help doctors find a balanced approach to treatment; an approach that is appropriate scientifically and medically, as well one suited to the patient personally and culturally.
(Kortmann, 2010)
Materials and Methods

The study was conducted targeting citizens of several Eastern and Western countries.

Our targeted eastern countries are Malaysia, India, China and Indonesia while the targeted western countries are Russia, Canada and the United Kingdom. Our target sample size was 200

The survey was created on Google Forms and distributed on social media platforms such as Facebook, VK, Instagram and WhatsApp. A Russian language version of the survey was also distributed.

The questions, including 2 case studies aimed to determine the respondent's level of belief in the paranormal, how it affects them personally, their views on mental disorders and their opinions on their treatment.

The survey is split into 3 parts: Demographics, Persona Beliefs, and Social influence.

Demographics consists of nationality, age group and medical background.

The questions in the Personal Beliefs and Social influence were created to explore how strongly their society and culture influences their sense of self, values, beliefs and everyday decision making.

Case Study 1

Jamil presented with unexplained, sudden onset neurosis. He was prescribed a course of antidepressant, paroxetine which manifested insignificant effects. However, he showed prominent improvement in his mental state after treatment by an Islamic healer who diagnosed him with jinn possession.

Case Study 2

Maria, 23 years old, underwent severe mental distress after conflict with a colleague at work. She developed delusion and sought treatment from a psychic. After ineffective treatment she began to look for a stronger folk healer. She refused her parents' suggestion to consult a psychiatrist.

After each case study, the respondents were required to give their answer on whether it was a medical or paranormal case, and if the treatment used was valid.

An opinion box was left at the end to share their views on this study.

A chi-square statistical test was performed to test the validity of all the responses. The statistical significance level was set as $\leq 0.05$

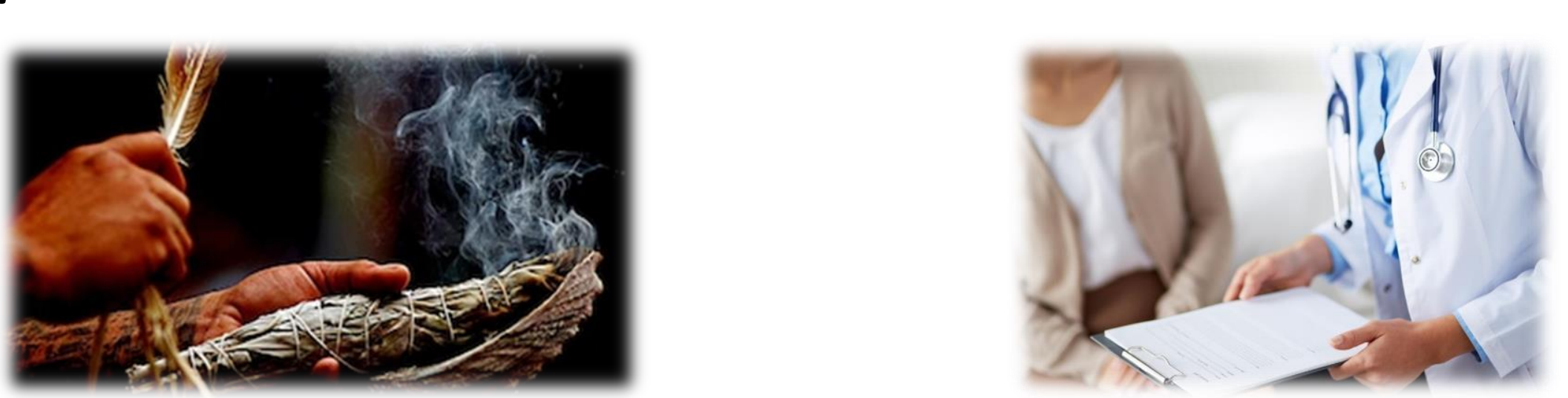

Results

A total of 226 responses were collected with 130 and 96 respondents from the East and the West respectively. The results are tabulated in Table 1

\begin{tabular}{|c|c|c|}
\hline \multicolumn{3}{|c|}{ Table 1} \\
\hline & East & West \\
\hline $\begin{array}{l}\text { Total respondents } \\
\text { (226) }\end{array}$ & $58 \%$ & $42 \%$ \\
\hline $\begin{array}{l}\text { Identified as } \\
\text { religious }\end{array}$ & $74 \%$ & $26 \%$ \\
\hline $\begin{array}{l}\text { Strong belief in } \\
\text { paranormal }\end{array}$ & $85 \%$ & $15 \%$ \\
\hline $\begin{array}{l}\text { Effectiveness of } \\
\text { spiritual healing }\end{array}$ & $55 \%$ & $45 \%$ \\
\hline $\begin{array}{l}\text { Preferred method: } \\
\text { of treatment }\end{array}$ & & \\
\hline $\begin{array}{l}\text { Mental health } \\
\text { professionals }\end{array}$ & $54 \%$ & $46 \%$ \\
\hline $\begin{array}{l}\text { Religious } \\
\text { healer/psychic }\end{array}$ & $90 \%$ & $10 \%$ \\
\hline
\end{tabular}

In the case studies, P-value $=4.68 \times 10-6$ was obtained through chi-square analysis proved that there is a strong relationship between East/West populations and their viewpoints on mental illness vs. possession.

There was also a strong relationship $(p=3.37 \times 10-5)$ between respondents' beliefs in spiritual healing and its effectiveness treating mental illness.

We received 70 constructive comments from the respondents regarding their personal idea of mental illness and its connection to culture in the realm of religious/paranormal.

\section{Some notable opinions include:}

"I had depression long before I realized. I didn't know what was going on, my parents didn't either. When it became really bad, tried getting help but my parents didn't believe in it nor supported me because of religious and cultural beliefs. After years I am able to understand how both medicine, therapy and my religion helps. My parents believed medicine would help once then they turned back to religion when it came back. They still don't fully understand nor want to accept it. They still don't believe it's real and just an illness fully."

Anonymous, Age 18-24, India

"Not knowing the nature of psychological illness, a person begins to associate with something that cannot be explained (often it is something religious or fictional). A person simply does not want to know more about his illness. is enough for him that he has found the "culprit". It's silly."
Conclusion

The study revealed that Eastern populations are far more religious and superstitious than their Western counterparts and have higher belief in the effectiveness of spintual healing to treat mental disorders. According to our findings, these beliefs wer firmly instilled into them from youth in large part by family and friends, in religious gatherings and media. As such, mental illness is still considered a taboo and a source of shame and embarrassment especially in Eastern cultures. Often, claiming to be possessed or spiritually inflicted is better accepted than own parents refused to give her medical treatment in favor of religious methods against her will. The practice of consulting religious figures, shamans and exorcisms indicates the idea that what modern western science considers a mental illness, in their perspective is not an organic disease but instead an infliction of the soul by unnatural forces.

This difference of approach can be explained by the secular view of mental health held by Western societies stemming from biopsychosocial understanding of the causes, manifestations and consequences of mental illness (Gureje et al, 2015). Additionally, the Western medicine approach is based on hypothetica deduction where it clearly divides health from the disease whereas the Eastern approach uses inductive method that unbalanced state (Wang, 2016). As such, the Western view allows the opportunity for education and open discussion of the topic within the general public, leading to better awareness and thus increased acceptance of mental illness in their societies.

This study provides an insight into the importance of developing holistic approach to integrate culture into diagnosis and advanced research should be executed to further explore methods for more inclusive treatment plans, which would include continued education on part of the doctors, better informed patients, as well as the development of an established and internationally adopted treatment guideline to ensure a more harmonious and effective experience.

\section{References}

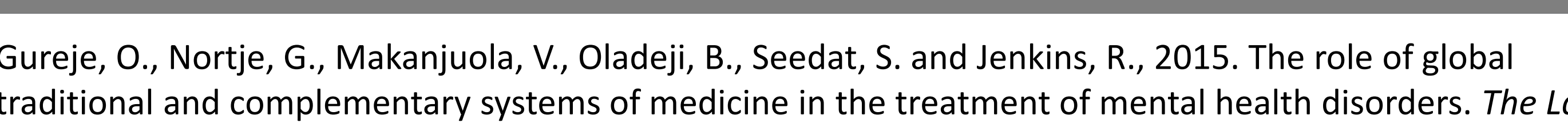

sychiatry, 2(2), pp. 168-17)

Kortmann, Frank. "Transcultural Psychiatry: From Practice To Theory". Transcultural Psychiatry, vol 47,
2010, pp. 203-223. SAGE Publications, do: 10.1177/1363461510368892. Accessed 12 Apr 2020.

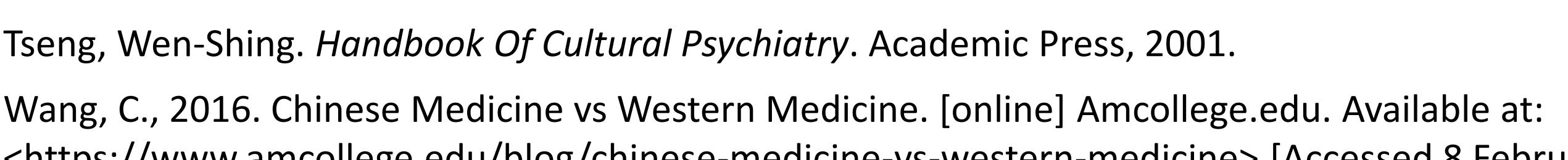

\section{Contact}

For further enq
+60142237350

Subsequently, We are available for a meeting on zoom

Time: Apr 11, 202103 :00 PM Amsterdam, Berlin, Ronte, Soch Th, Viena

Meeting ID: 5901515421 